\title{
A CROW ON A BARE BRANCH: A COMPARISON OF MATSUO BASHō'S HAIKU "KARE-EDA-NI..." AND ITS ENGLISH TRANSLATIONS
}

\author{
Elin Sütiste
}

\section{Introduction}

This paper aims to describe, compare and analyse different shifts that have occurred in the translation of Matsuo Bashō's haiku "Kare-eda-ni..." into English. With the help of close reading, attention is paid to the interference of the original haiku's features (such as syllables, seasonal word kigo, cutting word kireji, imagery etc.) with the poetic standards of the target culture (e.g., characteristics like title, rhyme, number of lines etc.)

As evidenced by the bulk of translations ${ }^{1}$ and the time-span during which these have been made, "Kare-eda-ni..." has fascinated Western translators since the beginnings of haiku ${ }^{2}$ translations. The text corpus used here consists of 32 English translations composed from 1899 until 2000 (see appendix). ${ }^{3}$

As is generally known, Japanese poetry is based on the 5- and 7-syllable patterns. Although the original haiku texts are presented in Japanese in the monolinear form, translations usually follow their underlying structure of 5-7-5 syllables and render a haiku in the form of three lines. However, this has not always been the case. Haiku was introduced to the West rather recently, at the turn of the 20th century. As there was no corresponding form for haiku in the West and haiku itself was a novelty, Japanese haiku was paralleled for some time and degree to epigram, as is evident from some of the first writings on haiku, e.g. B. H. Chamberlain's "Bashō and the Japanese epigram" (1902), or William Porter's anthology of translations, entitled A Year of Japanese Epigrams (1911) etc (Kawamoto 2000: 47, Kuriyama 1983: 80). By today, haiku as a literary form has become widely recognized also in the West, and the translations hardly follow the model of epigram anymore. Also, haiku does not exist only in the form of translations today; original haikus are composed widely all over the world. Still, not all the features of the original Japanese haiku are considered necessary for the "Western" or translated haiku. For example, whereas original haikus composed in the West seem to follow the requirement of 17 syllables rather keenly, the translations often disregard the exact number of syllables. As shown below, this requirement is often replaced with adherence to a general concept of haiku as a short poem of three, often symmetrically organized lines. The presentation of haiku in the form of three (and symmetrical) lines can be

\footnotetext{
${ }^{1}$ Often also referred to as "target texts" (TTs).

${ }^{2}$ Haiku is a term invented by Masaoka Shiki in the 19th century for denoting an independent, 17-syllable poem; before him, one could talk about hokku that was a beginning verse for a linked poetry sequence haikai no renga (or haikai renga, haikai referring to the playful style of renga, "linked poetry"). Although it was not unusual to write hokku, which would not be followed by the rest of the chain, hokku retained its status of an (at least possible) opening verse of a longer poem until Shiki's "reform" (see, e.g. Kuriyama 1983: 78). However, since we are now looking at pre-Shiki "independent" hokku as self-contained poems, I will use the term "haiku" here.

${ }^{3}$ Of the 32 translations considered here, 27 were collected together in the appendix of Toury 1993. To these I have added 5 more translations (nos 28-32) found from other sources than those used by Toury.
} 
evidently regarded as a more relevant, although conventional, marker of the literary form named "haiku" than the exact number of syllables (cf Sugiwara 1996 who uses the term "three-lined poem" to denote namely a translated haiku).

\section{Background of the Source Text (ST)}

$\begin{array}{ll}\text { kare-eda-ni } & \text { on a withered branch } \\ \text { karasu-no tomari-keri } & \text { a crow is perched } \\ \text { aki-no kure } & \text { autumn evening }\end{array}$

Bashō (1644-1694) wrote this haiku in the year 1680, and it is often considered to be a marker of the beginning of Bashō's mature style.

It should be mentioned that "Kare-eda-ni..." was not the first text to explore the topic of a crow sitting on a withered branch. First, there exists a set phrase in Chinese meaning "a chilly-looking crow on a bare tree" (Shiki, cit. Ueda 1991: 59) which is assumed to have been familiar also to Bashō. Secondly, Bashō had written a very similar haiku several years before this one (see paragraph 5.2 below). Both texts are accompanied by paintings, all three of which present a treatment of the topic of a withered tree and a crow (or crows, since on the painting that is assumed to be the earliest, there are 27 crows depicted altogether). Thus, Bashō's haiku has been often seen as an adaptation of an ancient Chinese phrase or a painting title. A close connection has also been found between this particular haiku and a renga verse cited in a 16th centurycollection, Hakuhatsushu (Yamamoto, cit. Ueda 1991: 60): evening crow -
in a bare tree on the mountain peak
a voice

\author{
yūgarasu \\ mine no kareki ni \\ koe wa shite
}

\section{Comparison of ST's and TTs' features}

\section{Title}

Three TTs of 32 (nos $5,7,13$ ) have added titles to their translations: nos 5 and 7 have an identical title, "A CROW ON A BARE BRANCH", while no 13 is entitled as "THE END OF AUTUMN". Title is not a feature belonging to the genre of haiku, thus it is apparently with the purpose of bringing the text closer to the target audience that titles have been considered necessary to the translations.

Title is a semantically powerful key to interpretation as it is the first thing that tells us "what is the following text going to be about". Thus, the titles of translations nos 5 and 7 inform us that the poems are about a crow on a bare branch, suggesting that we might be dealing with a snapshot of nature, while translation no 13 guides us to contemplate about the end of autumn, and possibly about other, more philosophical subjects connected with the idea of "end". Here it is interesting to note that Stewart, the translator of the TT no 13, has rendered the ambiguity of both meanings of aki-no kure 
(1. autumn evening; 2. late autumn; see also below) in his translation, presenting one interpretation in the title and another in the body text:

THE END OF AUTUMN

Autumn evening: on a withered bough

A solitary crow is sitting now.

\section{Syllables and lines}

17 syllables, divided into three lines of 5, 7 and 5 syllables, is often said to be the differentia specifica of haiku. However, it is also said that exception confirms the rule, and in the case of this haiku we are namely dealing with an exception, as it contains 19, not 17 syllables:

$\begin{array}{ll}\text { kare-eda-ni } & 5 \\ \text { karasu-no tomari-keri } & 9 \\ \text { aki-no kure } & 5\end{array}$

Out of the 32 English translations, only four (nos 13, 16, 17, 24) contain 19 syllables (it should be noted here that in counting the syllables in English translations, I have not taken into account the mute syllables, mainly the mute -ed of past simple and past participle). Only one translation (no 16) follows the syllabic structure of the ST of the lines of 5,9 and 5 syllables. (On the other hand, it should be noted that at the first sight, without counting the syllables, translation no 16 leaves an impression of a "less typical" haiku than many other translations, mainly because of the extensive use of enjambement and added epithets. Thus there appears a controversy in the markers of a form "haiku" here.) The average number of syllables in translations is ca 15 - less than in the ST. (This, of course, can be explained by the difference in the syllable composition in Japanese and in English, the Japanese syllable consisting always of one or two sounds only, while in English words like 'branch' or 'night' are also monosyllabic.) The smallest number of syllables in translations is 10 (nos 10, 14, 20 and 31), and the largest 31 (no 3).

It is interesting to note that two translations (nos 7 and 12, by Yasuda) follow the typical haiku syllabic structure more exactly than the ST itself, containing 17 syllables, arranged into lines of 5, 7 and 5 syllables. The translator has in a way "improved" the original text, eliminating its deviance from the rule in his translations.

In general, however, it is clear that the retaining of the original number of syllables has not been considered of primary importance in the translations. Most translations (27 out of 32) have simply rendered the text in the form of 3 lines, 5 TTs (nos $2,4,5,10,17)$ have preferred an even number of lines, having thus taken English poetic forms as their model (cf Toury 1993: 19-20). Although the exact number of syllables does not seem to be important, many translations (14 out of 32) have organized syllables into symmetrical lines. Apart from the TTs nos 7 and 12 that follow the number of syllables (17) of a typical haiku, and the TT no 16 that follows the syllabic pattern of "Kare-eda-ni..." (19 syllables in lines of 5-9-5), and the TTs nos 2 and 4 that use an even number of lines and can thus be regarded as oriented towards "domestic" literary models, 
the other 9 have adopted syllabic organization of some form of symmetry that is not reducible to any specific literary model.

\section{Alliteration, assonance, rhyme}

Because of the relative simplicity of the phonetic and syllabic systems as well as the lack of word stress in the Japanese language, there is no rhyme in Japanese poetry. Still, one can speak about alliteration and assonance, which, due to "the high incidence of vowels and the incisive cleanness of the single consonant /.../" can be "highly effective" (Bownas, Thwaite 1972: iii). According to Bownas and Thwaite (ibid.), certain vowels and consonants are conventionally associated with certain modes and tones, for example, "alliteration by the repetition of $k / \ldots /$ may give an effect of melancholy" as in Bashō's "Kare-eda-ni..." (Bownas, Thwaite 1972: iiii).

Assonance and alliteration have been widely used also in the translations; in some cases also rhyme has been introduced. Assonance has been employed in 17 TTs, most notable cases being the repetitions of [ai] as in alighted/nightfall (nos 11, 16, 21, 22, 29) and [ou] as in gloaming/slowly/lonely/crow (nos 3, 4, 7, 12).

Alliteration is almost entirely focused on the sound [b] as in bare/branch/bough (nos $3,4,5,10,14,16,19,20,21,22,29,30)$. Only in one case out of 13 occurrences of alliteration also [r] is repeated (no 14, rook/roosts).

Perfect rhyme occurs in 4 cases: now/bough in 3 cases (nos 7, 11, 12), and night/light in one case (no 3). In a few cases, also imperfect rhyme has been used, e.g. bough/crow (nos 23, 24). Noticeable is also the repetition of ch: in 8 cases, there appears a co-occurrence of perched/branch.

Although it has not been the aim of the translators to re-create the repetition of the [k]-sound in their TTs, many of them have employed so-to-say domestic means to add suggestiveness to their translations. The most conspicuous in this respect is TT no 3 , which has created a complicated network of sound-repetitions:

autumn-orange, gloaming-slowly-lonely-crow-(bough), deepens-gloaming-intowithered-is-sitting, back-bough, 'gainst-fading-(a), withered-the, night-light

The autumn gloaming deepens into night;

Back 'gainst the slowly-fading orange light,

On withered bough a lonely crow is sitting.

\section{Kigo, "seasonal word"}

The seasonal word, kigo, is generally a required part of each haiku. This indicates the season in which the haiku is set. "In the haiku world view, then, all people, things, and events can be fully appreciated and take on their proper meanings only in the context of temporal flow and the rhythms of nature" (Kuriyama 1983: 81-82). In Bashō's haiku "Kare-eda-ni...", the seasonal word is aki-no kure, "autumn evening". 


\section{Seasonal word aki-no kure}

It can be argued that aki-no kure has two possible interpretations. Aki means autumn, and kure means basically "the end". In the classical literature, kure refers both to the end of a day, evening, as well as to the end of year, one of the four seasons etc. (cf. Matsumura et al. 1988: 417). Thus, according to Oseko, aki-no kure "is interpreted in two ways: 1. autumn evening, 2. late autumn" (Oseko 1990: 2). Nagata in his Haiku Saijiki (Dictionary of Haiku Seasonal Words) explains the entry of aki-no kure followingly: Aki-no kure the dusk of an autumn day. In the old times, aki-no kure as a seasonal word referred to mid-autumn, being distinguished from bosh $\bar{u}$, "end of autumn". Bosh $\bar{u}$ refers to the 9th month of the lunar calendar, while aki-no kure to the 8th month" (Nagata 1980: 507). Thus, according to Nagata, aki-no kure does not refer to the end of autumn, but only to the end of a (mid)autumn day. On the other hand, according to Yamamoto, this confusion of the two meanings of aki-no kure was present already in Genji Monogatari (in the beginning of the 11th century), and had not been solved by the time Bashō lived (17th century) (Yamamoto 1957: 32). Yamamoto also refers to the fact that three out of six Bashō's haikus that contain the expression aki-no kure, bear a date that falls within the last 10 days of the 9th lunar month (that is already considered to be the end of autumn). (The dates of the other 3 haikus are not clear.) Although Yamamoto admits that this fact alone does not need to bear any significance on the interpretation of aki-no kure ${ }^{4}$, he proposes to see "end of autumn" as the seminal meaning of the expression aki-no kure that, with time, had weakened and broadened to include also the meaning of "autumn evening" (Yamamoto 1957: 32-33). Thus, taking into account the basic meanings of the word kure, we might contend that there remains a certain ambiguity, a possibility to take into account both meanings when reading this haiku.

In either case, the central connotation of both "autumn evening" and "the end of autumn" is desolateness, forlornness. However, since the majority of translations considered here interpret aki-no kure as "autumn evening" (as opposed to "the end of autumn"), let us focus briefly on the concept of "autumn evening". Aki-no kure in its meaning of "autumn evening" is related to other similar seasonal words like aki-no yügure "autumn dusk" and aki-no yübe "autumn evening". As to the semantics of the seasonal word "autumn evening", then it is a deep-rooted tradition to see autumn evening as an embodiment of a sense of forlornness, solitude, desolateness: "In Japan, the forlornness of "autumn evening" constitutes a sort of normative assumption" (Kawamoto 2000: 2). To illustrate the strength of this assumption I will quote a passage from Kawamoto: "Declaring, "Recently, when I heard the sound of a temple bell in the mountains at dusk, I didn't feel at all forlorn," the haikai poet Fūkoku (d. 1701) composed a three-line hokku verse to this effect. Mukai Kyorai (1651-1704) responded with strongly worded criticism: "This is lacking in refinement. A 'mountain temple', 'autumn dusk', and 'bell at dusk' all epitomize forlornness. To go off on a tangent and say that it is not forlorn to the ear is simply being willful."“ (Kawamoto 2000: 1). Thus, to use Kawamoto's term, the forlornness of an autumn evening constitutes an "essential implication" in the tradition of Japanese literature.

\footnotetext{
${ }^{4}$ Interpretation of aki-no kure as "autumn evening" in Bashō's time is evidenced by entries in works like Adzuma nikki and Arano (see Yamamoto 1957: 33).
} 
In Bashō's haiku "Kare-eda-ni...", the idea of forlornness and desolateness is further amplified by the image of crow(s) on a withered tree branch ${ }^{5}$, the keyword here being "withered" as it relates most directly to the idea of end, autumn, and sorrow and solitude connected with these.

How is the idea of forlornness, conveyed in the ST by the seasonal word aki-no kure and amplified by the image of crow(s) on a withered branch, transmitted in the translations of this haiku by Bashō? Obviously, the words "autumn dusk" or "autumn evening" do not have as strong and inevitable connotations in English as in the Japanese tradition. Quoting Kawamoto: "In the Eigo Saijiki (Seasonal Topics in English), under the entry for "autumn evening" it is stated that: "In Japan, 'autumn evening' elicits a sense of sorrow. However in England and America this does not seem to be the case in every instance. There is no firmly-established association between the two." This statement is followed by a variety of examples including both ones that can be recognized as containing a sorrowful sentiment and ones that cannot. Regardless of whether of not a sense of forlornness is conveyed in a given poem treating autumn dusk, the phrase in and of itself does not inevitably convey a sense of forlornness in English" (Kawamoto 2000: 5).

Thus, taking into account the above-said, we may say that a translator who wishes to convey the idea of forlornness expressed in "Kare-eda-ni..." might find that only using the words like "autumn evening" fails to create a mood or interpretation corresponding to the ones of the source text. As we noted earlier, the idea of forlornness of an autumn evening is amplified in the original text by the image of a withered branch, and this is also a possibility for a translator. The images of an autumn evening and a withered branch together may help to direct a reader's thoughts towards the sense of sorrow and solitude connected with an idea of end - end of day, autumn, autumn day, or one's life. Perhaps it would not be an overstatement to say that Bashō's haiku contemplates (among other things) about the inevitable end of all things, well expressed in the image of autumn evening scenery. However, to my eye, many of the English translations seem to fail to convey this sense of forlornness inherent in the source text, resulting in some cases in little more than neutral descriptions, for example no 10:

Autumn evening -

A crow on a bare branch.

In the following section we will consider the treatment of the ST's images in the translations.

\section{The treatment of images in the TTs}

\subsection{Kare-eda-ni, "on a withered branch"}

In this section we shall look at the first image of the ST, kare-eda-ni, which can be translated as "on a withered branch" ("withered branch" is also the most frequently used

\footnotetext{
${ }^{5}$ On the treatment of karasu, "crow" and kare-eda, "withered branch" in the translations, see below.
} 
translation of kare-eda, being employed in 8 TTs, exceeding thus the six uses of "bare branch").

Matsumura et al. (1988: 340), under the entry of kare-eda-ni interpret this haiku by Bashō in following words: "quiet, lonesome autumn evening, with a crow sitting on a withered, completely leafless branch". On the other hand, Yamamoto argues that the kare-eda-ni present in this haiku is not a branch of a tree with no leaves (that belongs to the season of winter), but according to Shida Yoshihide, a branch of a tree that has lost its vital force.

Kare-eda is composed of two words: kareru, "to wither, die, lose vital force", and $e d a$, "branch". The seminal meaning of kareru is thus the loss of vigour and vitality, the process ending in death. Thus, taking into account also the above-said, kare-eda refers to a branch that, most probably, has lost its leaves in the process of becoming withered, dying. To convey this part of the ST, translators have used the following epithets: "withered" (16 TTs), "dead" (2 TTs), "bare" (10 TTs), "leafless" (4 TTs), and "barren" (2 TTs). All these adjectives are rather close in meaning, although some nuances differ. Thus, "bare" and "leafless" are synonyms, referring to the state of having no leaves, being bare. However, the lack of leaves does not necessarily have to be connected with the idea of the movement towards death: for example, in spring we are more likely to speak of "bare" or "leafless" trees than of "withered" or "dead" trees, "bare" and "leafless" referring in that case to the state of yet not having leaves, while "withered" and "dead" do not carry this connotation. "Barren", on the other hand, implies another nuance, also slightly different from the other adjectives: for example, a tree is barren when it does not bear fruit, but it does not necessarily imply the meaning of the tree being "completely" dead. Thus, among the adjectives chosen to convey kare-, "bare", "barren" and "leafless" appear as marked. It should be noted that the preference to use words "bare" and "barren" may well be connected with the wish to create alliteration as in bare branch or bare bough. The shift in meaning in the choice of "bare" or "leafless" can be said to be generalization, and the shift to "barren", specification.

$E d a$ is ordinarily translated as "branch", although in some cases "bough" and "twig" can be also used. The difference between these is mainly that of the size: the "biggest" of these branches in the English usage is "bough", for which there is also a special term in Japanese: $\bar{o}$-eda "big branch". "Twig", on the other hand, is considerably smaller than a branch or a bough, and this is also rendered in Japanese by ko-eda, meaning "small branch, twig".

Among the 32 TTs, 20 have preferred to render $e d a$ as "branch"; 9 have opted for "bough"; 2 have chosen "tree", one translation has used "tree branch", and another one, "limb". On the background of the unmarked "branch", other variants appear as marked, the shift to "bough" and "limb" being characterized as specification; the choice of "tree" as generalization, and that of "tree branch" as explication.

Two translations (nos 16 and 21) have chosen to double the adjectives describing the branch:

16. Bare barren branch on which a crow has alighted autumn Nightfall darkening 
21. When the crow arrives

on the bare, withered branch

true night has come

By repeating closely related adjectives in the descriptions of the branch, the two translations emphasize particularly the poem's autumnal mood and the idea of the inevitable end.

\subsection{Karasu, "crow"}

The prevalent translation of karasu has been "crow" which is also its dictionary meaning. In two cases (nos 2 and 14), "rook" has been used instead of "crow", making thus a shift towards specification.

Japanese language generally does not differentiate between singular and plural (except for a few words which have acquired a kind of idiomatic status, e.g. "kodomo" child - "kodomo-tachi" children; "watashi" I - "watashi-tachi" we etc.). Thus, it is impossible to state with certainty, how many crows did Bashō have in mind composing this haiku. Among the 32 translations, however, there is only one (no 2) that speaks of more than one crow ("... some rooks / Are perched upon a withered branch").

The haiku by Bashō presently under discussion was preceded several years before by another, a very similar poem with only a slight difference:

kare-eda-ni

karasu-no tomari-taru ya

aki-no kure
On a withered branch

a crow stood perched autumn dusk. ${ }^{6}$

There exist paintings associated with both of these haikus. To the haiku we are discussing here there belong two paintings, one by Bashō himself and another by his disciple Kyoriku. Quoting Oseko, in both of these paintings "...there is only one crow perched on a branch. But in his several years earlier painting with the other haiku [kare-eda-ni / karasu-no tomari-taru ya / aki-no kure], seven crows are perched on the branches of a large tree entwined with a coloured ivy, and 20 more crows are flying over in the sky.

Bashō changed 27 crows to just one crow. What caused him to change the number of crows?

He found out that one crow can express what he wanted to express much better than 27 crows" (Oseko 1990: 2).

Thus, the treatment of the ST's karasu as a single crow has its support in the paintings accompanying the haiku originally. In addition to that, interpretative considerations play their role here also: the figure of one crow suggests the idea of loneliness obviously better than that of many crows. Besides, many translations have followed this interpretation further, describing the crow as "solitary" or "lonely", emphasizing thus the idea of loneliness even more, for example:

3. ... On withered bough a lonely crow is sitting

\footnotetext{
${ }^{6}$ I have used the translation by Kawamoto/Collins (Kawamoto 2000: 102).
} 


\title{
7.... A crow alone is perching
}

\section{2.... A crow alone is perching}

\section{3. ... A solitary crow is sitting now}

It should be noted, however, that the version "a crow alone" of translations nos 7 and 12 may direct a reader's mind onto a rather different, even slightly humorous path of thought: reading the line "A crow alone is perching ", the reader may begin to wonder who else (besides the crow) could/should be perching there on that bough.

In one case the translator has rendered also the colour of the crow: in TT no 17, we are told that the crow is black:

\author{
A black crow \\ Has settled himself \\ On a leafless tree \\ Fall on an autumn day
}

Thus, the treatments of karasu as "rook", or in plural, or with epithets like "solitary" or "black", appear to be marked as opposed to the unmarked rendering of karasu as "crow". "Rook" and the use of plural, then, are occurrences of specification; added epithets, on the other hand, the cases of expressive amplification.

\subsection{Tomarikeri, "is perched"}

Tomarikeri is a form of tomaru which refers to an end of movement, stop, and also to the state of already having stopped, rest etc. When used in connection with birds or insects, tomaru can be rendered in English by the words "perch", "alight", "settle", "sit" (Kenkyusha's New College Japanese-English Dictionary). All these variants have been employed in the translations; besides these, also "roost", "arrive", "balance", and "squat".

Keri is the auxiliary verb of past and exclamation (Oseko 1990: 2). It follows that tomarikeri refers to rather a static situation with no significant movement going on. Thus we could say that a more or less neutral rendering of tomarikeri would be an employment of one of the closely related equivalents for tomaru mentioned above, in a form that would convey rather a static than dynamic situation. These considerations have been observed by the majority of translations. There are two TTs (nos 21 and 27) that use the verb with the semantics of activity and in the Present Simple tense, adding thus dynamics to the situation. Another translation (no 20) uses the present participle form of the verb "balance" in adjectival function, and doing so, also renders the crow's state more dynamical than in other cases. Finally, two TTs (nos 10 and 24) do not convey any idea of activity at all, omitting verbal element altogether. This does not affect the specifically static aspect of the ST.

In speaking of the semantics of the "motion words" used in the translations, there appear some more or less slight shifts in the meaning. While "perch", "alight" and 
"settle" all refer both to the arrival (of a bird or insect) and the state after that, then "sit" and "squat" are used rather to describe the state of already being perched or settled. (In any case, when speaking of the verb "to sit", the height from which the descending motion can take place cannot be as great as in the case of the verbs "to perch", "to alight" or "to settle".) Now, the verb "roost" has a nuance that the other verbs do not necessarily convey: "to roost" means to settle or to be settled for the night, to be prepared for night's sleep. For example, translation no 30 explains well this difference:

On a bare branch

a crow has settled down to roost.

In autumn dusk.

Again, the verb "balance" does not render the idea of descending motion. In the form of past participle ("balanced") it can convey the image of being already settled and the cessation of any significant movement; on the other hand, in the form of present participle, "balancing" conveys precisely the idea of at least some movement, of a state where equilibrium has yet not been achieved. A similar aspect appears also in connection with the word "settle". In translation no 27, "settle" is used in the Present Simple tense, "settles":

On the dead branch,

a crow settles -

autumn evening.

The tense used here adds dynamics to the situation: the crow is in the process of alighting, sitting down. In all other cases, "settle" has been used in static forms.

The most dynamic of all is the verb "arrive" (TT no 21). The tense used is Present Simple, which adds its share of an image of motion. This is further amplified by the use of narrative syntax:

When the crow arrives

on the bare, withered branch

true night has come.

Summing up, we can say that all the verbs contributing to a greater degree of dynamics than is observable in the ST, and also the words that add a semantically different nuance to the original tomarikeri, appear as marked here. The verbs contributing to the static state of the crow (esp. verbs used in the form of past participle and the tense of Present Perfect, to some extent also Present Continuous) seem to draw less attention to themselves than the verbs used, for example, in Present Simple tense. The result of the use of the more dynamic verb forms is an emphasis on the action taking place, which thus seems to distract a reader's attention away from the other connotations of the haiku such as created by the image of a withered branch and an autumn evening. 


\subsection{Aki-no kure, "autumn evening"}

As already mentioned, aki is the word for "autumn", and kure means basically "the end". When interpreted in the sense of the close of a day, kure can refer to different stages of the evening: nightfall, dusk, as well as twilight (Kenkyusha's New College JapaneseEnglish Dictionary). According to Concise Oxford Dictionary, in English, different stages of evening have separate names: thus, evening is a general term for "close of day, esp. from about 6 p.m. (or earlier sunset) to bedtime". However, within this general term of evening the different stages of the process when the light fades and night begins can be differentiated: the "closest" to day is twilight as this refers to the "light from sky when sun is below horizon in morning or (usu.) evening" (ibid.). Twilight is thus a phenomenon of both morning and evening sky (although it usually refers to evening light), the common element for both being the sun that is just below the horizon. Synonymous with the evening twilight is the term "gloaming" (which thus does not include the ambiguity between morning and evening). The next step towards night is dusk that is defined as "darker stage of twilight" (ibid.). And the closest of all to night is "nightfall" which is defined simply as "end of daylight" (ibid.) that is about the time when the real darkness and night begin.

The 32 translations have rendered the ST's aki-no kure differently, preferring in some cases to specify a point of time within evening, "dusk" and "nightfall" being the most employed words ("dusk" 6 times, translations nos 14, 20, 23, 24, 25, 30; "nightfall" 5 times, in nos $6,11,16,18,29$ ). More than one third of the translations (nos 4, 7, 8, 9, $10,12,13,15,19,26,27,28)$ have rendered aki-no kure as "autumn evening" without further temporal specification. "Gloaming" and "twilight" have been used only once (translations nos 3 and 22, respectively); "eve", an archaic form of "evening, has been employed twice (translations nos 1 and 5). In addition to the above, also a paraphrase, "Fall on an autumn day" (no 17) has been used; besides, in translation no 21, aki-no kure has been rendered by a shift from evening into night: "true night has come".

In the case of translation no 13 we saw how the translator had retained the ambiguity of the expression aki-no kure by presenting one meaning of it in the title, "END OF AUTUMN", and the other one in the body text. This competing interpretation of aki-no kure has been used in translation no 2 where no reference to the time of the day has been made:

The end of autumn, and some rooks Are perched upon a withered branch.

On the other hand, there are 4 cases (translations nos $1,7,12,13$ ) where the situation is rendered as occurring here and now, bringing the reader closer to the scene:

1. On a withered branch

a Crow is sitting

This autumn eve. 
7. Autumn evening now

A crow alone is perching

On a leafless bough.

12. On a withered bough

A crow alone is perching;

Autumn evening now.

13. Autumn evening: on a withered bough

A solitary crow is sitting now.

Of course, it may be argued that the use of "now" is simply used for a rhyme for the word "bough". Nevertheless, apart from the rhyme, it still effects the connotations of "here and now".

Besides temporal concretization, also the appearance of the autumn evening is explicated in some cases. For example, compared with the ST's laconic (although rich with connotations) expression aki-no kure ("autumn evening"), translation no 3 presents us an entire landscape painting:

The autumn gloaming deepens into night;

Back 'gainst the slowly-fading orange light,

On withered bough a lonely crow is sitting.

Although other additions to the "autumn evening" are more modest, they, too, present interpretative comments on its nature:

4. 'Tis a dreary autumn evening

16. ...autumn / Nightfall darkening

21. ... true night has come

22. ... autumn nocturne

24. ... In the gathering autumn dusk

All these additions convey a sense of melancholic, forlorn, or even almost gothic feeling of an autumn evening, also emphasizing in some cases the process of the night's arrival, the growing and deepening darkness. Together with the picture of a crow sitting on a withered branch, these renditions of aki-no kure may point a reader's attention to the possibility of interpreting the poem in the romantic/gothic tradition of E. A. Poe's "The Raven" - which is a background knowledge for probably a majority of English-speaking readers.

Thus, all the cases besides the neutral substitutions ("autumn evening") can be regarded as marked substitutions, the types of substitution being paraphrase ("fall on an 
autumn day", TT no 17); archaization ("eve" pro "evening", TTs nos 1 and 5); temporal specification ("dusk", "nightfall", "twilight"); expressive amplification (e.g. "dreary autumn evening"), and temporal concretization ("autumn evening now", "this autumn eve").

\section{Kireji, "cutting word"}

There remains another important aspect of a haiku to be spoken about, namely, the kireji, which is usually rendered in English as "cutting word". It is considered to be a vital part of a haiku and it is presented in a form of a short word like ya or kana. In the haiku "Kare-eda-ni...", kireji is keri.

In English, kireji is usually not conveyed by a word, although attempts have been made, for example the word "Lo!" in the translation no 4:

Lo! A crow sits on a bare bough,

'Tis a dreary autumn evening.

Still, more often, a kireji is presented in English by means of punctuation: "In English the effect [of kireji] is roughly equivalent to a line break punctuated by a colon, long dash, or ellipsis" (Kuriyama 1983: 81).

The technique of kireji, then, involves a cut, a caesura that "divides the poem into two parts and forces the reader's imagination to somehow relate or reconcile these two parts" (Kuriyama 1983: 81). Asano explains the nature of kireji in the following manner: "To "cut" means the end of predication in a broad sense /.../ i.e., the expression "The wind... is cool" (subject + predicate) is cut at the end. This expression is normally called a "sentence". To use kireji means that one can express this "cutting" [without constructing a whole sentence]. "Akikaze $y a$ " is equal to "Oh, the autumn wind is blowing!" (cit. Yamada-Bochynek 1985: 256).

According to Yamada-Bochynek (1985: 257-258), a structure containing a kireji can be seen as an equation or juxtaposition of two parts of the poem, formally expressed as " $\mathrm{A}=\mathrm{B}$ ", "=" representing the kireji and "A" and "B" the two parts of a poem. Thus, our poem would look like the following:

$\begin{array}{llll}\text { kare-eda-ni } & \text { / karasu-no tomari-keri } & \text { / aki-no kure } \\ \text { on a withered bough } & \text { / a crow is sitting (;) / } & \text { autumn evening } \\ & \text { A }\end{array}$

"According to Asano, then, the function of kireji lies in the fact that it provides a poem with a structural separation while expressing simultaneously the poet's exuberant feelings. /.../ It should be further emphasized that owing to this function even one noun can convey the information which otherwise necessitates the whole "clause", i.e., "subject + predicate" (Yamada-Bochynek 1985: 256).

Thus, reading Bashō's haiku, we should remember to include a caesura at the end of the second line: 


$\begin{array}{ll}\text { kare-eda ni } & \text { on a withered branch } \\ \text { karasu-no tomari-keri// } & \text { a crow is perched// } \\ \text { aki-no kure } & \text { autumn evening }\end{array}$

The translation of kireji seems to be one of the most difficult problems, which involves a lot more than simply choosing between different punctuation marks or words like "Lo!". First of all, it is deeply connected with the overall interpretation of the source text, and it may be conveyed by means of the position of images, graphics, syntax, different punctuation marks, or of no punctuation marks at all. In the following section I will attempt to elucidate my point of view on kireji.

As we understood from the remarks above made by Asano and YamadaBochynek, the function of kireji is to "cut" a poem in two in order to enable then the equation of the two halves resulting from cutting. This means that having realized the fact of the separation and of the underlying similarity of the two halves of a poem, one's mind should be encouraged to move between these two parts, contemplating their implicit sameness. Now, let's turn our look on the translations of Bashō's "Kare-eda-ni..." and see how different translators have approached this aspect and what has resulted from their choices. I will proceed by considering punctuation marks that can be used to convey kireji, and discuss the role of graphics, syntax, position of images etc. in connection with these.

\subsection{Punctuation}

Different translators of this haiku have solved the problem of kireji differently, using punctuation marks of various degrees of intensity, and some not employing punctuation marks at all. Out of 32 translations, 7 do not use any punctuation marks (nos $1,7,8,15,16,17,21) ; 8$ use a dash $(-)($ nos $6,10,11,19,23,25,27,32) ; 6$ use a colon (:) (nos 9,13,14,22,24,26); 4 employ a semicolon (;) (nos 3,5,12,20); 2 use a comma (,) (nos 2, 4); another 2 use an ellipsis (...) (nos 18,29), and 3 use a full stop (nos 28, 30,31).

\subsubsection{The use of no punctuation marks}

In the cases where no punctuation marks are used to mark a "cut" in the text, other features acquire significance. For example, in helping to decide whether or where one should make a pause, syntax (the means of relating or not relating different images) becomes important: e.g. in the case of translation no 8, the preposition "in" at the beginning of the third line ties this line immediately with the two previous ones. On the other hand, in the TT no 17, it is namely syntax that determines a pause between the third and the fourth lines: syntax combines the first three lines into one unit, from which the fourth line is detached. And, differently from other translations, the TT no 21 employs a truly narrative syntax that does not allow for a cut of thought at all.

In cases where there are no punctuation marks used to mark a pause, typographical means may obtain a great significance. For example, the TT no 15 uses an 
indent at the beginning of the third line, which brings this line to the foreground and detaches it from the first two. And, the TT no 1 uses a capital letter at the beginning of the third line, thus also distinguishing it from the previous line.

\subsubsection{Colon (:) and dash (一)}

Although dash and colon appear rather similar to some extent, there are still some differences in nuance. For one, as colon is often used before illustrations or explanations, it seems to be inherently "tendentious". Therefore the position of images becomes important here, as it guides (together with the use of colon) our interpretation of a text. Thus, the position of the image "autumn evening" in the first line renders the following two lines as a kind of illustration to the first image, while the position of the same image in the third line makes it an explanation of the situation presented in the first two lines, for example:
9. Autumn evening:
26. On a withered branch
A crow perched
A crow is perched:
On a withered bough
An autumn evening

In speaking of the interrelation of the position of images and colon, translation no 24 may be very telling: here, the image of autumn evening is placed between the images describing the branch and the crow (which in the ST belong together). The colon is used at the end of the second line, which results in the third line being raised to the centre of attention:

\section{On a leafless bough \\ In the gathering autumn dusk: \\ A solitary crow!}

Thus, in this text, the image of crow acquires the foremost importance (which is further amplified by the use of exclamation mark at the end, as well as the graphics that lead us "step by step" to the last line).

Dash appears to be less "tendentious" than colon, and performs the function of "cut" more neutrally (although, as in informal writing dash is often used instead of colons and semicolons, there may occur some "interference" between the three), e.g.:

\footnotetext{
6. On a withered branch a crow has settled autumn nightfall.
} 


\subsubsection{Semicolon (;)}

As semicolon is less "tendentious" than dash or colon, it appears to be one of the best means to convey a break in thought where the "equality" of the two sides resulting from the cut is expected, for example:

12. On a withered bough A crow alone is perching; Autumn evening now.

\subsubsection{Comma (,)}

When compared to dash, colon, semicolon, or ellipsis, comma is certainly the weakest among these. Still, comma is also a "separator", guiding us to make a slight pause. However, in the case of poetry, that may acquire a different nuance.

In the case of poetry where there is no consistent meter or syntax to mark the continuation of the text, the end of line itself may acquire a meaning of pause even with no punctuation marks used. In such circumstances there is no instructions how long should a pause last; on the other hand, a comma in a similar situation instantly marks a pause as a relatively short one, e.g. TT no 4:

Lo! A crow sits on a bare bough,

'Tis a dreary autumn evening.

(Of course, here is used also another, syntactic device for connecting the two lines: the beginning of the second line by “"Tis".)

\subsubsection{Ellipsis (...) and full stop (.)}

Ellipsis and full stop are also well-suited means to convey a sense of (untendentious) break (although in some cases they may be considered as even too strong markers of a break), e.g.:
18. On a withered bough a crow has settled...
28. On a withered branch, autumn nightfall.
A crow is perched.
An autumn evening.

The use of ellipsis creates an effect of a rather long-lasting pause, with the end of the line as if slowly fading away. On the other hand, the use of full stop renders the pause as an abrupt cut. 


\subsection{Other remarks on the relations of the translation of kireji and the rest of TT}

Even if kireji is formally translated in an explicit manner, there may be other aspects that so-to-say weigh it down. For example, the TT no 4 has attempted to convey kireji in a way similar how it is done in Japanese: by a short word that expresses the focusing of attention:

Lo! A crow sits on a bare bough,

'Tis a dreary autumn evening.

However, in the above case, "Lo!" does not fulfil the function of kireji of cutting a poem into two as it appears in the very beginning. Thus it signals the need to pay attention to the whole text, not to balance its two parts.

Another remark has to be made in connection with the relation of kireji and the overall balance of a text. If there is a feature in a TT that draws main attention to itself, kireji may fail to perform its function. For example, the alliteration and assonance used in the TT no 14 are so conspicuous that other aspects of the text are left in shadow. Similarly, the translation no 30 pays great attention to the second line, first by using an indent, and secondly, by using "extra-"wording to explain the reason of the crow sitting on the branch:

On a bare branch

a crow has settled down to roost.

In autumn dusk.

This way, although a strong marker of break - full stop - is used, the balance of the two parts of the text is doubtful, as the weight of the second line has been made so obvious. The result is that the first and the third line appear as little more than background commentaries for the second line.

It has hopefully become clear from the above-said that the solving of the problem of kireji-translation is closely connected with the rendering of other aspects of the text, and, at the bottom line, with the overall interpretation of the source text.

\section{Summary}

Looking at the 32 translations of Bashō's haiku in their chronological succession, one cannot help but notice a general tendency towards the establishment of a certain standard of this translation. Especially the first translations differ considerably from the last ones, for example, translations nos 25 through 29 offer only minor variations when compared to translations nos 2 to 5 . The later translations are much more "literal", while the first ones have taken more liberty in their rendition of the original text. As noted already before, this can be explained by the lack of haiku tradition at the beginning of haiku translations. With time, however, haiku has become an established literary form also in 
the West that has resulted in lesser adherence to the "domestic" literary models in the translation.

As for the formal features of a haiku (e.g., the presence of kigo and kireji), these are generally conveyed in some way or another also in the translations. However, another set feature, the number of syllables, is not considered to be of primary importance in the translations. The tendency is rather towards rendering a translation in the form of three lines. Sometimes the original pattern of 5-7(9)-5 syllables in three lines is also conveyed by transferring it into symmetrical three lines, the concept of 5-7(9)-5 being thus replaced by the concept of symmetry.

Thematically, four larger blocks can be distinguished: translations which openly focus attention on the picture of the crow on a branch (e.g. TTs nos 5, 7, 24, 30); translations which (compared to other translations with marked components) do not explicate keys for further interpretation (e.g., TTs nos 8, 9, 10, 19, 26, 28); translations that attempt to explicate the concept of forlornness rendered in Japanese in the first place by the seasonal word aki-no kure (e.g., TTs nos 3, 7, 12, 13); and translations that relate the ST's images with the target culture connotations. Here, one cannot but recall E. A. Poe's poem "The Raven" which, for an English-speaking reader, certainly acts as background knowledge when interpreting Bashō's "Kare-eda-ni...". These connotations refer to the romantic/gothic understanding of autumn and crow as a bird of ill-omen (cf. for example, translations nos $4,21,31$ ). 


\section{References}

Bownas, Geoffrey and Thwaite, Anthony (1972). The Penguin Book of Japanese Verse. Penguin Books.

Carter, Steven D. (1991). Traditional Japanese Poetry: An Anthology. Stanford, California: Stanford University Press.

Concise Oxford Dictionary of Current English, 7th ed. (1987). Bombay: Oxford University Press.

Kawamoto, Kōji (2000). The Poetics of Japanese Verse. Tokyo: University of Tokyo Press.

Kececioglu, John. http://webster.cs.uga.edu/ kece/Personal/Poems/basho.html

Kenkyusha's New College Japanese-English Dictionary, 4th ed. (1995). Kenkyusha.

Kuriyama, Shigehisa (1983). "Haiku” in: Kodansha Encyclopedia of Japan. Vol. 3. Tokyo: Kodansha.

Matsumura et al. (1988). Kogojiten. (The Dictionary of Archaic Words.) Tokyo: Obunsha.

Nagata, Yoshinao (1980). Haiku Saijiki. (The Dictionary of Haiku Seasonal Words.) Tokyo: Kinensha.

Oseko, Toshikaru (1990). Bashō's Haiku. Vol. 1. Tokyo.

Sugiwara, Katsuya (1996). "San-kō-shi to shite no haiku - R. H. Buraisu ni yoru haiku no hon'yaku ni tsuite" ("Haiku as Three-Lined Poem: On the Translation of Haiku by R. H. Blyth") in: Hikaku Bungaku Kenkyū. No. 69, December. Tokyo: University of Tokyo, Society of Comparative Literature.

Toury, Gideon (1993). ““Translation of Literary Texts" vs. "Literary Translation": A Distinction Reconsidered" in: Recent Trends in Empirical Translation Research. Joensuu: University of Joensuu.

Ueda, Makoto (1991). Bashō and His Interpreters. Stanford, California: Stanford University Press.

Yamada-Bochynek, Yoriko (1985). Haiku East and West. Bochum: Studienverlag Brockmeyer.

Yamamoto, Kenkichi (1957). Bashō. Sono kanshō to hihyō. (Bashō. Appreciation and criticism.) Tokyo: Shinchōsha. 


\section{Appendix}

1 On a withered branch

a Crow is sitting

This Autumn eve.

Aston, 1899

2 The end of autumn, and some rooks

Are perched upon a withered branch.

Chamberlain, 1902

3 The autumn gloaming deepens into night; Back 'gainst the slowly-fading orange light,

On withered bough a lonely crow is sitting.

Walsh, 1916

4 Lo! A crow sits on a bare bough,

'Tis a dreary autumn evening.

Miyamori, 1930

5 A CROW ON A BARE BRANCH

A crow is perched on a bare branch;

It is an autumn eve.

Miyamori, 1932

6 On a withered branch

a crow has settled -

autumn nightfall.

Henderson, 1933

7 A CROW ON A BARE BRANCH

Autumn evening now

A crow alone is perching

On a leafless bough.

Yasuda, 1947

8 On a withered branch

A crow is perched

In the autumn evening.

Blyth, 1949

9 Autumn evening:

A crow perched

On a withered bough.

Blyth, 1952

10 Autumn evening -

A crow on a bare branch.

Rexroth, 1955

11 On a withered branch

A crow has alighted -

Nightfall in autumn.
12 On a withered bough

A crow alone is perching;

Autumn evening now.

Yasuda, 1957

13 THE END OF AUTUMN

Autumn evening: on a withered bough

A solitary crow is sitting now.

Stewart, 1960

14 On a bare branch

A rook roosts:

Autumn dusk.

Bownas, 1964

15 A crow

Perched on a withered tree

In the autumn evening.

Blyth, 1964

16 Bare barren branch on

which a crow has alighted autumn

Nightfall darkening.

$?, 1964$

17 A black crow

Has settled himself

On a leafless tree

Fall on an autumn day.

Yuasa, 1966

18 On a withered bough

a crow has settled...

autumn nightfall.

Amann, 1969

19 On a bare branch

A crow is perched -

Autumn evening.

Ueda, 1970

20 Barren branch;

balancing crow;

autumn dusk.

Cohen, 1972

21 When the crow arrives on the bare, withered branch true night has come.

Cohen, 1972

22 Bare branch and a crow balanced on the twilight: autumn nocturne.

Cohen, 1972 
23 On a leafless bough A crow is perched The autumn dusk.

Giroux, 1974

24 On a leafless bough In the gathering autumn dusk: A solitary crow!

Britton, 1974

25 On a withered tree branch a crow perches autumn dusk.

Sawa, 1978

26 On a withered branch A crow is perched:

An autumn evening.

Aitken, 1978

27 On the dead branch a crow settles autumn evening.
28 On a withered branch, A crow is perched.

An autumn evening.

Oseko, 1990

29 on a bare branch a crow has alighted... autumn nightfall.

Ueda, 1991

30 On a bare branch

a crow has settled down to roost.

In autumn dusk.

Carter, 1991

31 On a dead limb squats a crow. Autumn night.

Kececioglu

32 On a withered branch a crow has perched autumn dusk.

Kawamoto/Collins, 2000 